\title{
The Influence of Reaction Conditions on the Oxidation of Cyclohexane via the In-Situ Production of $\mathrm{H}_{2} \mathrm{O}_{2}$
}

\author{
Caitlin M. Crombie ${ }^{1}$ Richard J. Lewis ${ }^{1}$. Dávid Kovačič ${ }^{1}$. David J. Morgan ${ }^{1,2} \cdot$ Thomas E. Davies $^{1}$. \\ Jennifer. K. Edwards ${ }^{1} \cdot$ Martin Skov Skjøth-Rasmussen ${ }^{3} \cdot$ Graham J. Hutchings $^{1}$
}

Received: 1 May 2020 / Accepted: 27 May 2020 / Published online: 10 June 2020

(c) The Author(s) 2020

\begin{abstract}
The oxidation of cyclohexane via the in-situ production of $\mathrm{H}_{2} \mathrm{O}_{2}$ from molecular $\mathrm{H}_{2}$ and $\mathrm{O}_{2}$ offers an attractive route to the current industrial means of producing cyclohexanone and cyclohexanol (KA oil), both key materials in the production of Nylon. Herein we demonstrate that through the in-situ production of $\mathrm{H}_{2} \mathrm{O}_{2}$ supported AuPd nanoparticles catalyse the formation of KA oil under conditions where activity is limited when using molecular $\mathrm{O}_{2}$, with no loss in catalytic activity observed upon re-use. The effect of key reaction parameters, including reaction temperature, catalyst mass and $\mathrm{H}_{2}: \mathrm{O}_{2}$ ratio are evaluated.
\end{abstract}

\section{Graphic Abstract}

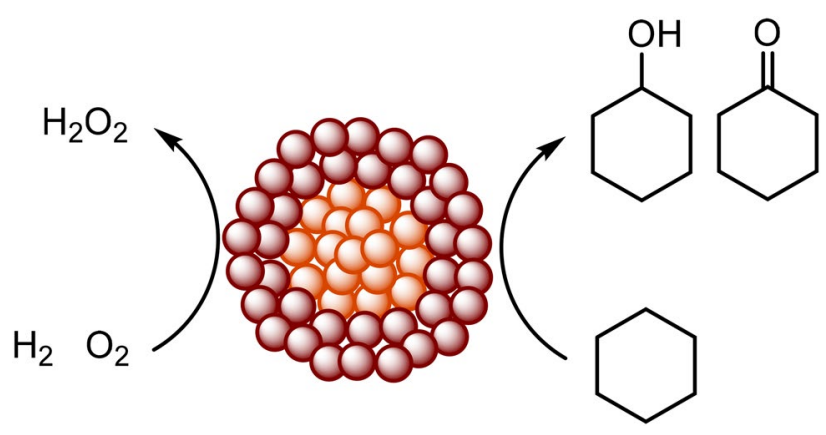

Keywords Gold · Palladium · Hydrogen peroxide · Cyclohexane oxidation · Green chemistry

Caitlin M. Crombie and Richard J. Lewis have contributed equally to this work.

Electronic supplementary material The online version of this article (https://doi.org/10.1007/s10562-020-03281-1) contains supplementary material, which is available to authorized users.

Graham J. Hutchings

Hutch@ cardiff.ac.uk

1 School of Chemistry, Cardiff University, Main Building, Park Place, Cardiff CF10 3AT, UK

2 HarwellXPS, Research Complex at Harwell (RCaH), Didcot OX11 OFA, UK

3 Haldor Topsøe A/S, Haldor Topsøes Allé 1, 2800 Kongens Lyngby, Denmark

\section{Introduction}

The oxidation of cyclohexane and production of cyclohexanone and cyclohexanol (collectively known as KA oil) is a key industrial process in the production of adipic acid and caprolactam, which in turn are starting materials for Nylon-6,6 and Nylon-6. The current industrial means of producing KA oil via the high temperature $\left(>150^{\circ} \mathrm{C}\right)$ aerobic oxidation of cyclohexane typically utilises homogeneous cobalt salts and limits conversion to below 5\% in order to maintain high selectivity towards desired products. Initially cyclohexyl hydroperoxide (CHHP) is the major product that decomposes to form cyclohexanone and cyclohexanol, with carboxylic acids also produced [1,2]. At higher conversion 
rates significant amounts of ring-opened by-products, such as 6-hydroxyhexanoic acid, in addition to a range of $\mathrm{C}_{1}-\mathrm{C}_{5}$ (di)acids are produced [3]. In addition to the high energy costs associated with the use of elevated temperatures the difficulties associated with separation of the catalyst from product streams has driven significant research into the replacement of cobalt salts with heterogeneous catalysts, with immobilised precious metal catalysts of particular interest [4-6]. While further studies have reported that significantly lower reaction temperatures can be utilised by replacing molecular $\mathrm{O}_{2}$ with tert-butylhydroperoxide [7-9] or pre-formed $\mathrm{H}_{2} \mathrm{O}_{2}$, although it should be noted that $\mathrm{H}_{2} \mathrm{O}_{2}$ efficiency is typically limited $[10,11]$, often due to catalysed $\mathrm{H}_{2} \mathrm{O}_{2}$ decomposition [12-14].

Furthermore, several economic and environmental drawbacks associated with the use of commercial $\mathrm{H}_{2} \mathrm{O}_{2}$ exist, namely those associated with the anthraquinone oxidation (AO) process, the means by which the vast majority of $\mathrm{H}_{2} \mathrm{O}_{2}$ is produced on an industrial scale. Despite the high efficiency of the $\mathrm{AO}$ process it is only economically viable when operated at a large scale, necessitating the centralisation of production [15]. Hence, $\mathrm{H}_{2} \mathrm{O}_{2}$ is typically transported and stored at concentrations in excess of $70 \mathrm{wt} \%$ prior to dilution at point of final use. While the low stability of $\mathrm{H}_{2} \mathrm{O}_{2}$, undergoing rapid decomposition in the presence of relatively mild temperatures, requires the use of stabilising agents such as acetic acid [16] or phosphoric acid [17]. With the use of such additives often passing on additional costs to the end user, associated with reactor corrosion and their removal from product streams.

Therefore, the in-situ production of $\mathrm{H}_{2} \mathrm{O}_{2}$ from molecular $\mathrm{H}_{2}$ and $\mathrm{O}_{2}$ would offer an attractive alternative for the selective oxidation of cyclohexane, avoiding the numerous drawbacks associated with the use of pre-formed $\mathrm{H}_{2} \mathrm{O}_{2}$. In particular the use of in-situ produced $\mathrm{H}_{2} \mathrm{O}_{2}$ would lead to significantly reduced process costs, associated with lower reaction temperatures and the use of cheaper reaction feeds, namely $\mathrm{H}_{2}$ and $\mathrm{O}_{2}$.

\section{Experimental}

\subsection{Catalyst Preparation}

Bi-metallic $0.5 \% \mathrm{Au}-0.5 \% \mathrm{Pd} / \mathrm{TiO}_{2}$ catalysts have been prepared (on a weight basis) by a conventional wet-impregnation procedure, based on methodology previously reported in the literature [18]. Catalysts produced via a wet-impregnation procedure have been widely studied due to simplicity and ease with which this approach can be scaled to meet industrial application. The procedure to produce $0.5 \%$ $\mathrm{Au}-0.5 \% \mathrm{Pd} / \mathrm{TiO}_{2}(2 \mathrm{~g})$ is outlined below, with a similar methodology utilized for all mono- and bi-metallic catalysts.
Aqueous acidified $\mathrm{PdCl}_{2}$ solution $\left(1.667 \mathrm{~mL}, 6 \mathrm{mg} \mathrm{mL}^{-1}\right.$, Sigma-Aldrich) and aqueous $\mathrm{HAuCl}_{4} \cdot 3 \mathrm{H}_{2} \mathrm{O}$ solution ( $0.8263 \mathrm{~mL}, 12.25 \mathrm{mg} \mathrm{mL}^{-1}$, Strem Chemicals) were mixed in a $50 \mathrm{~mL}$ round-bottom flask and heated to $65^{\circ} \mathrm{C}$ with stirring (1000 rpm) in a thermostatically controlled oil bath, with total volume fixed to $16 \mathrm{~mL}$ using $\mathrm{H}_{2} \mathrm{O}$ (HPLC grade). Upon reaching $65{ }^{\circ} \mathrm{C}, \mathrm{TiO}_{2}(1.98 \mathrm{~g}$, Degussa, P25) was added over the course of 5 min with constant stirring. The resulting slurry was stirred at $65^{\circ} \mathrm{C}$ for a further $15 \mathrm{~min}$, following this the temperature was raised to $95^{\circ} \mathrm{C}$ for $16 \mathrm{~h}$ to allow for complete evaporation of water. The resulting solid was ground prior to calcination (static air, $400{ }^{\circ} \mathrm{C}, 3 \mathrm{~h}$, $20^{\circ} \mathrm{C} \mathrm{min}^{-1}$ ). We have previously demonstrated that calcination of supported AuPd catalysts at a temperature of $400{ }^{\circ} \mathrm{C}$ is required to produce a highly active, stable catalyst and results in the adoption of Au-core PdO-shell nanoparticle morphology when using a range of oxide supports [19].

\subsection{Catalyst Testing}

Note: reaction conditions used within this study operate under the flammability limits of gaseous mixtures of $\mathrm{H}_{2}$ and $\mathrm{O}_{2}$.

\subsection{Direct Synthesis of $\mathrm{H}_{2} \mathrm{O}_{2}$ from $\mathrm{H}_{2}$ and $\mathrm{O}_{2}$}

Hydrogen peroxide synthesis was evaluated using a Parr Instruments stainless steel autoclave with a nominal volume of $50 \mathrm{~mL}$, equipped with a PTFE liner and a maximum working pressure of $14 \mathrm{MPa}$. To test each catalyst for $\mathrm{H}_{2} \mathrm{O}_{2}$ synthesis, the autoclave liner was charged with catalyst $(0.01 \mathrm{~g})$ and solvent $\left(5.6 \mathrm{~g}\right.$ methanol and $\left.2.9 \mathrm{~g} \mathrm{H}_{2} \mathrm{O}\right)$. The charged autoclave was then purged three times with $5 \% \mathrm{H}_{2} /$ $\mathrm{CO}_{2}$ (100 psi) before filling with $5 \% \mathrm{H}_{2} / \mathrm{CO}_{2}$ to a pressure of $420 \mathrm{psi}$, followed by the addition of $25 \% \mathrm{O}_{2} / \mathrm{CO}_{2}$ (160 psi). Pressure of $5 \% \mathrm{H}_{2} / \mathrm{CO}_{2}$ and $25 \% \mathrm{O}_{2} / \mathrm{CO}_{2}$ are given as gauge pressures. The reaction was conducted at a temperature of $20{ }^{\circ} \mathrm{C}$, for $0.5 \mathrm{~h}$ with stirring (1200 rpm). Reactor temperature was controlled using a HAAKE K50 bath/circulator using an appropriate coolant.

$\mathrm{H}_{2} \mathrm{O}_{2}$ productivity was determined by titrating aliquots of the final solution after reaction with acidified $\mathrm{Ce}\left(\mathrm{SO}_{4}\right)_{2}$ $(0.0085 \mathrm{M})$ in the presence of ferroin indicator. Catalyst productivities are reported as $\mathrm{mol}_{\mathrm{H}_{2} \mathrm{O}_{2}} \mathrm{~kg}_{\text {cal }}^{-1} \mathrm{~h}^{-1}$.

\subsection{Cyclohexane Oxidation via the In-Situ Production of $\mathrm{H}_{2} \mathrm{O}_{2}$}

Cyclohexane oxidation has been evaluated using a Parr Instruments stainless steel autoclave with a nominal volume of $50 \mathrm{~mL}$, equipped with a PTFE liner and a maximum working pressure of $14 \mathrm{MPa}$. To test each catalyst for cyclohexane oxidation, the autoclave was charged with catalyst $(0.05 \mathrm{~g})$, 
t-butanol solvent (6.375 g, Sigma Aldrich) and cyclohexane (2.125 g, $25 \mathrm{mmol}$, Sigma Aldrich) with mesitylene (0.43 g, Sigma Aldrich) used as an internal standard. The charged autoclave was then purged three times with $5 \% \mathrm{H}_{2} /$ $\mathrm{N}_{2}(0.7 \mathrm{MPa})$ before filling with $5 \% \mathrm{H}_{2} / \mathrm{N}_{2}$ to a pressure of $2.9 \mathrm{MPa},\left(2.51 \mathrm{mmol} \mathrm{H}_{2}\right)$ followed by the addition of $25 \%$ $\mathrm{O}_{2} / \mathrm{CO}_{2}\left(1.1 \mathrm{MPa}, 4.77 \mathrm{mmol} \mathrm{O}_{2}\right.$ ). The temperature was then increased to $80^{\circ} \mathrm{C}$ with stirring (500 rpm). Once the desired temperature was reached the reaction mixture was stirred $(1200 \mathrm{rpm})$ for $17 \mathrm{~h}$. After the reaction was complete the reactor was cooled in ice to a temperature of $15^{\circ} \mathrm{C}$, upon which a gas sample was taken for analysis by gas chromatography, using a Varian CP-3380 equipped with a TCD detector and a Porapak Q column. Product yield was determined by gas chromatography using a Varian 3200 GC equipped with a FID and CP Wax 42 column.

Quantification of the peroxide intermediate cyclohexyl hydroperoxide (CHHP) is determined by reacting a $2 \mathrm{~mL}$ aliquot of the post reaction mixture with an excess of triphenyl phosphine $(0.13 \mathrm{~g}, 0.5 \mathrm{mmol})$. Reaction of triphenyl phosphine and CHHP produces cyclohexanol and hence comparison of GC analysis for cyclohexanol pre and post treatment with triphenyl phosphine can determine the yield of CHHP.

Catalytic conversion of $\mathrm{H}_{2}$ was determined using a Varian 3800 GC fitted with TCD and equipped with a Porapak Q column.

$\mathrm{H}_{2}$ conversion (Eq. 1), cyclohexane conversion (Eq. 2) and selectivity to all $\mathrm{C}_{6}$ products based on $\mathrm{H}_{2}$ (Eq. 3) is defined as follows:

$\mathrm{H}_{2}$ Conversion $(\%)=\frac{\mathrm{mmol}_{\mathrm{H}_{2}(t(0))}-\mathrm{mmol}_{\mathrm{H}_{2}(t(1))}}{\mathrm{mmol}_{\mathrm{H}_{2}(t(0))}} \times 100$

Cyclohexane Conversion $(\%)=\frac{\mathrm{mmol}_{\operatorname{Cyclo}(t(0))}-\mathrm{mmol}_{\operatorname{Cyclo}(t(1))}}{\mathrm{mmol}_{\operatorname{Cyclo}(t(0))}} \times 100$

$\mathrm{C}_{6}$ Product Selectivity $(\%)=\frac{\text { Total product }(\mathrm{mmol})}{\mathrm{H}_{2} \text { conversion }(\mathrm{mmol})} \times 100$

Note Given the relatively low conversion rates observed within this work total product yield is used as a substitute for cyclohexane conversion.

\subsection{Catalyst Reusability in the Oxidation of Cyclohexane via In-Situ Production of $\mathrm{H}_{2} \mathrm{O}_{2}$}

In order to determine catalyst reusability, a similar procedure to that outlined above for the oxidation of cyclohexane is followed utilising $0.15 \mathrm{~g}$ of catalyst. Following the initial test, the catalyst was recovered by filtration, washed with cyclohexane and dried $\left(30^{\circ} \mathrm{C}, 17 \mathrm{~h}\right.$, under vacuum); from the recovered catalyst sample $0.05 \mathrm{~g}$ was used to conduct a standard cyclohexane oxidation experiment.

\subsection{Catalyst Characterisation}

A Thermo Scientific K-Alpha ${ }^{+}$photoelectron spectrometer was used to collect XP spectra utilising a micro-focused monochromatic $\mathrm{Al} \mathrm{K}_{\alpha} \mathrm{X}$-ray source operating at $72 \mathrm{~W}$. Data was collected over an elliptical area of approximately $400 \mu \mathrm{m}^{2}$ at pass energies of 40 and $150 \mathrm{eV}$ for high-resolution and survey spectra, respectively. Sample charging effects were minimised through a combination of low energy electrons and $\mathrm{Ar}^{+}$ions, consequently this resulted in a $\mathrm{C}(1 \mathrm{~s})$ line at $284.8 \mathrm{eV}$ for all samples. All data was processed using CasaXPS v2.3.20 rev 1.2H using a Shirley background, Scofield sensitivity factors [19] and an electron energy dependence of -0.6 as recommended by the manufacturer.

Transmission electron microscopy (TEM) was performed on a JEOL JEM-2100 operating at $200 \mathrm{kV}$. Samples were prepared by dispersion in ethanol by sonication and deposited on 300 mesh copper grids coated with holey carbon film. Energy dispersive X-ray analysis (EDX) was performed using an Oxford Instruments X-Max ${ }^{\mathrm{N}} 80$ detector and the data analysed using the Aztec software.

Metal leaching was quantified using microwave plasmaatomic emission spectroscopy (MP-AES). Post reaction solid catalysts were digested $(0.01 \mathrm{~g}$ catalyst in $10 \mathrm{~mL}$ aqua-regia, $16 \mathrm{~h}$ ) prior to analysis using an Agilent $4100 \mathrm{MP}-\mathrm{AES}$.

\section{Results and Discussion}

Our initial studies investigated the efficacy of mono- and bimetallic $1 \% \mathrm{AuPd} / \mathrm{TiO}_{2}$ catalysts, prepared by a conventional wet-impregnation procedure, towards the direct synthesis of $\mathrm{H}_{2} \mathrm{O}_{2}$ from molecular $\mathrm{H}_{2}$ and $\mathrm{O}_{2}$ under reaction conditions not conducive towards $\mathrm{H}_{2} \mathrm{O}_{2}$ stability (Fig. S1). In keeping with our previous studies into the direct synthesis of $\mathrm{H}_{2} \mathrm{O}_{2}$ [20] as well as a range of selective oxidation reactions [21-24], the alloying of Au with Pd results in a synergistic enhancement in catalytic activity, with the $0.5 \% \mathrm{Au}-0.5 \%$ $\mathrm{Pd} / \mathrm{TiO}_{2}$ catalyst demonstrating far greater activity towards $\mathrm{H}_{2} \mathrm{O}_{2}$ formation than the mono-metallic analogues.

We have previously demonstrated that it is possible to catalyse the oxidation of cyclohexane via the in-situ production of $\mathrm{H}_{2} \mathrm{O}_{2}$, with AuPd nanoparticles immobilised onto zeolite-Y demonstrating appreciable rates of cyclohexane conversion (2.4\%) and product yield (74 $\mu \mathrm{mol})$ [25]. Interestingly these previous studies reported complete selectivity towards cyclohexanol, likely as a result of the short reaction times utilised. 


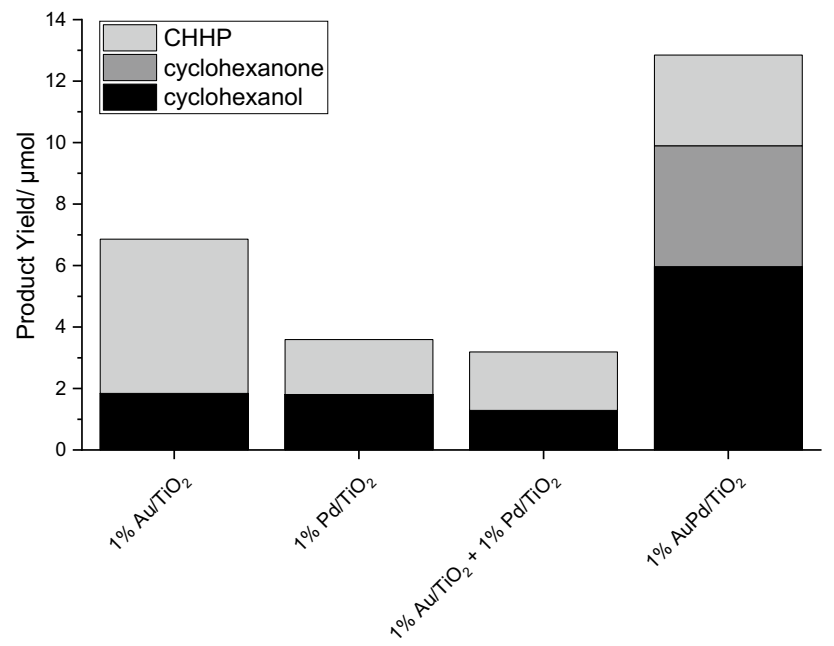

Fig. 1 Catalytic activity of AuPd supported catalysts towards the oxidation of cyclohexane. Reaction conditions Catalyst $(0.05 \mathrm{~g})$, cyclohexane (2.13 g, $25 \mathrm{mmol})$, t-butanol $(6.37 \mathrm{~g}), 5 \% \mathrm{H}_{2} / \mathrm{N}_{2}(420$ $\mathrm{psi}), 25 \% \mathrm{O}_{2} / \mathrm{N}_{2}(160 \mathrm{psi}), 17 \mathrm{~h}, 80{ }^{\circ} \mathrm{C} 1200 \mathrm{rpm}$. Note In the case of a physical mixture of the monometallic catalysts $0.025 \mathrm{~g}$ of each catalyst is used

Building on our initial results we next investigated catalytic efficacy towards cyclohexane oxidation, via the in-situ production of $\mathrm{H}_{2} \mathrm{O}_{2}$ (Fig. 1). It should be noted that under the reaction conditions used within this study no residual $\mathrm{H}_{2} \mathrm{O}_{2}$ was measured in post reaction solutions. This is perhaps unsurprising given the comparatively high reaction temperatures and long reaction times utilised within this study. However, our previous studies, have elucidated the ability of $\mathrm{H}_{2} \mathrm{O}_{2}$ to be synthesised under similar reaction conditions [25]. It can be seen that the activity of the $0.5 \% \mathrm{Au}-0.5 \%$ $\mathrm{Pd} / \mathrm{TiO}_{2}(12.8 \mu \mathrm{mol})$ catalyst greatly outperforms the analogous monometallic $1 \% \mathrm{Au} / \mathrm{TiO}_{2}(6.8 \mu \mathrm{mol})$ and $1 \% \mathrm{Pd} / \mathrm{TiO}_{2}$ $(3.6 \mu \mathrm{mol})$ catalysts. A physical mixture of the $1 \% \mathrm{Au} / \mathrm{TiO}_{2}$ and $1 \% \mathrm{Pd} / \mathrm{TiO}_{2}$ catalysts demonstrated considerably lower activity $(1.3 \mu \mathrm{mol})$ than that of the bi-metallic catalyst indicating the need for $\mathrm{Au}$ and $\mathrm{Pd}$ to be present as an alloyed species or in close proximity on the same support grain to achieve a synergistic enhancement in catalytic activity.

Importantly the activity of the $0.5 \% \mathrm{Au}-0.5 \% \mathrm{Pd} / \mathrm{TiO}_{2}$ catalyst under in-situ conditions (i.e. in the presence of $\mathrm{H}_{2}$ and $\mathrm{O}_{2}$ ) greatly outperforms that observed using $\mathrm{O}_{2}$ and is comparable to that seen when using preformed $\mathrm{H}_{2} \mathrm{O}_{2}$ (Fig. $\mathrm{S} 2$ ), clearly highlighting the benefits of the in-situ approach. This can be understood when considering the relatively low reaction temperatures utilised in this study, compared to that typically required when using $\mathrm{O}_{2}$ as an oxidant and the low stability of preformed $\mathrm{H}_{2} \mathrm{O}_{2}$, even at these mild temperatures.

Building on these promising initial results, and in an attempt to improve catalytic activity we next investigated the effect of a range of reaction conditions on the selective oxidation of cyclohexane. Time-on-line analysis was first evaluated (Fig. 2), in keeping with previous studies into the selective oxidation of cyclohexane [4, 26, 27] and cyclohexene [28] a clear induction period is observed, with no conversion of cyclohexane observed up to $3 \mathrm{~h}$. Beyond which total product yield gradually increases to a maxima of $18.6 \mu \mathrm{mol}$ over the time period studied. It should be noted that no conversion of cyclohexane is observed under similar reaction conditions utilising molecular $\mathrm{O}_{2}$ alone (Fig. $\mathrm{S} 2$ ). Under both aerobic and in-situ conditions we do not observe the formation of any products other than KA oil and CHHP, such as adipic acid. This is not unsurprising given the relatively mild conditions used within this work, with the production of adipic acid on an industrial scale catalysed by high concentrations of $\mathrm{HNO}_{3}$. Analysis of $\mathrm{H}_{2}$ and cyclohexane conversion, in addition to selectivity to all C6 products (cyclohexanone, cyclohexanol and CHHP) can be seen in Table $\mathrm{S} 1$ and reveals that $\mathrm{H}_{2}$ conversion is particularly high $(68 \%)$ even at short reaction times, with this metric increasing with time to near complete conversion over $24 \mathrm{~h}$. In a similar manner cyclohexane conversion increases with reaction time. However, it should be noted that the extent of cyclohexane conversion is particularly low in all cases $(<1 \%)$. This may be unsurprising given the vast excess of cyclohexane $(25 \mathrm{mmol})$ present in comparison to $\mathrm{H}_{2}(2.51 \mathrm{mmol})$. Given the limited product yield observed a reaction time of $17 \mathrm{~h}$ was chosen to evaluate other key reaction parameters.

XPS analysis of the $0.5 \% \mathrm{Au}-0.5 \% \mathrm{Pd} / \mathrm{TiO}_{2}$ catalyst at key time intervals (Table 1) reveals a stark shift in Pd: Au, possibly indicative of nanoparticle restructuring or agglomeration during the course of the reaction. With the possibility

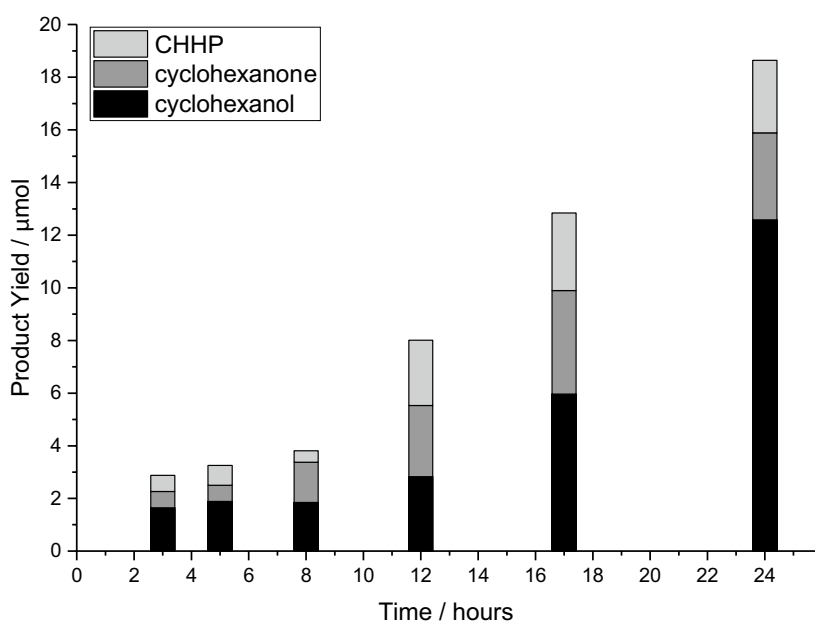

Fig. 2 Catalytic activity towards the selective oxidation of cyclohexane, via $\mathrm{H}_{2} \mathrm{O}_{2}$ synthesis as a function of reaction time over a $0.5 \%$ $\mathrm{Au}-0.5 \% \quad \mathrm{Pd} / \mathrm{TiO}_{2}$ catalyst. Reaction conditions Catalyst $(0.05 \mathrm{~g})$, cyclohexane $(2.13 \mathrm{~g}, 25 \mathrm{mmol})$, t-butanol $(6.37 \mathrm{~g}), 5 \% \mathrm{H}_{2} / \mathrm{N}_{2}(420$ psi), $25 \% \mathrm{O}_{2} / \mathrm{N}_{2}(160 \mathrm{psi}), 80{ }^{\circ} \mathrm{C} 1200 \mathrm{rpm}$ 
Table 1 Summary of XPS derived surface atomic concentrations of $\mathrm{Au}$ and $\mathrm{Pd}$ present in $0.5 \% \mathrm{Au}-0.5 \% \mathrm{Pd} /$ $\mathrm{TiO}_{2}$ catalyst as a function of reaction time

\begin{tabular}{lll}
\hline Time (h) & $\mathrm{Pd}: \mathrm{Au}$ & $\mathrm{Pd}^{0}: \mathrm{Pd}^{2+}$ \\
\hline 0 & 18.5 & 1.3 \\
3 & 34 & 1.6 \\
8 & 28.8 & 4.9 \\
17 & All Pd & 5.9 \\
24 & All Pd & 9.8 \\
\hline
\end{tabular}

of agglomeration supported by TEM analysis of the fresh and used $0.5 \% \mathrm{Au}-0.5 \% \mathrm{Pd} / \mathrm{TiO}_{2}$ catalyst (representative micrographs seen in Fig. S3). Although it should be noted that it was not possible to count a statistically relevant number of nanoparticles to generate an accurate mean particle size for the fresh and used catalysts. Perhaps more interesting is the significant increase in $\mathrm{Pd}^{0}: \mathrm{Pd}^{2+}$ ratio over the course of the reaction, with this value increasing from a value of 1.3 for the as prepared material to 9.8 after use in a $24 \mathrm{~h}$ reaction, likely due to the in-situ reduction of $\mathrm{Pd}^{2+}$.

The effect of varying reaction temperature was next studied (Fig. 3). While numerous studies have reported the beneficial effect of sub-ambient temperatures on the direct synthesis of $\mathrm{H}_{2} \mathrm{O}_{2}$, owing to an inhibition of $\mathrm{H}_{2} \mathrm{O}_{2}$ degradation pathways $[15,29]$, typically temperatures exceeding $140{ }^{\circ} \mathrm{C}$ have been explored for the oxidation of cyclohexane under aerobic conditions [30] as such a large conditions gap exists between the two key reaction steps. Temperatures between 50 and $140{ }^{\circ} \mathrm{C}$ were evaluated for cyclohexane oxidation via the in-situ production of $\mathrm{H}_{2} \mathrm{O}_{2}$, with the results shown in Fig. 3a (comparative data using molecular $\mathrm{O}_{2}$ as the oxidant seen in Fig. 3b). Below the autooxidation temperature of $140{ }^{\circ} \mathrm{C}$ conversion of cyclohexane using $\mathrm{O}_{2}$ alone is limited, with a significant improvement in total product yield observed through combining $\mathrm{H}_{2}$ and $\mathrm{O}_{2}$. Indeed, at temperatures below $80{ }^{\circ} \mathrm{C}$ no products are observed under purely aerobic conditions, highlighting the beneficial role of $\mathrm{H}_{2} \mathrm{O}_{2}$ production in the oxidation of cyclohexane.

The effect of catalyst mass was next investigated (Fig. 4) with total product yield increasing steadily with catalyst content up to a catalyst mass of $0.05 \mathrm{~g}(12.8 \mu \mathrm{mol})$. Beyond which a significant decrease in product yield, in addition to product selectivity (Table S2) is observed, likely due to increased catalytic activity towards $\mathrm{H}_{2} \mathrm{O}_{2}$ degradation and $\mathrm{H}_{2} \mathrm{O}$ formation (via hydrogenation and decomposition pathways) with a similar mass dependence previously reported for the direct synthesis of $\mathrm{H}_{2} \mathrm{O}_{2}$ [31]. This is supported by $\mathrm{H}_{2}$ conversion analysis (Table $\mathrm{S} 2$ ) which indicates minimal difference in $\mathrm{H}_{2}$ conversion rates beyond a catalyst mass of $0.01 \mathrm{~g}$. Alongside the significantly lower product yields at higher catalyst masses this suggests $\mathrm{H}_{2}$ is utilised unselectively in the hydrogenation of $\mathrm{H}_{2} \mathrm{O}_{2}$.

Investigation into the effect of stirring rate was next carried out (Fig. 5) with an optimal stirring speed of $1200 \mathrm{rpm}$
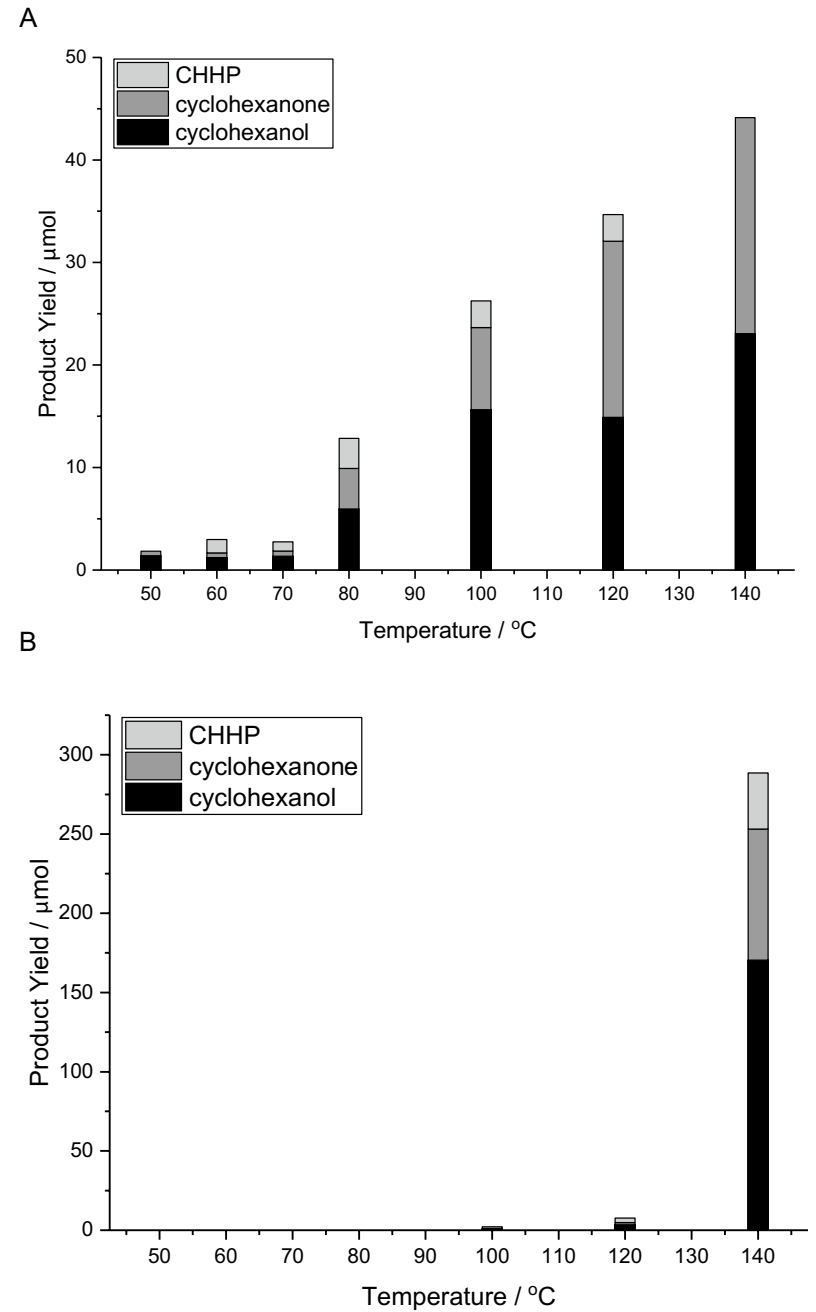

Fig. 3 The effect of reaction temperature on the oxidation of cyclohexane to $\mathrm{KA}$ oil over a $0.5 \% \mathrm{Au}-0.5 \% \mathrm{Pd} / \mathrm{TiO}_{2}$ catalysts (a) using in-situ generated $\mathrm{H}_{2} \mathrm{O}_{2}$ and (b) using molecular $\mathrm{O}_{2}$ as the oxidant. Reaction conditions Catalyst $(0.05 \mathrm{~g})$, cyclohexane $(2.13$, $25 \mathrm{mmol}$ ), t-butanol (6.37 g), $5 \% \mathrm{H}_{2} / \mathrm{N}_{2}$ (420 psi), $25 \% \mathrm{O}_{2} / \mathrm{N}_{2}(160$ psi), $17 \mathrm{~h}, 80{ }^{\circ} \mathrm{C} 1200 \mathrm{rpm}$. Note When using $\mathrm{O}_{2}$ as oxidant $25 \% \mathrm{O}_{2} /$ $\mathrm{N}_{2}$ (160 psi) is used and $\mathrm{N}_{2}(420 \mathrm{psi})$

determined. Below this stirring rate it is considered that the reactants are not sufficiently mixed, and the reaction is limited by reactant diffusion, while at stirring speeds exceeding $1200 \mathrm{rpm}$ the reaction is inhibited by cavitation, where available catalytic sites are limited due to centrifugal forces (see Schematic S1) [32]. Determination of $\mathrm{H}_{2}$ conversion and cyclohexane conversion (Table S.3) reveals a similar trend to that seen for total product yield, with these metrics reaching a maxima at $1200 \mathrm{rpm}\left(94 \% \mathrm{H}_{2}\right.$ conversion and $0.05 \%$ cyclohexane conversion), before decreasing at increased stirring speed $\left(78 \% \mathrm{H}_{2}\right.$ conversion and $0.03 \%$ cyclohexane conversion at $1400 \mathrm{rpm}$ ) indicating that $\mathrm{H}_{2} \mathrm{O}_{2}$ production and in turn cyclohexane oxidation is limited at increased stirring speeds. 


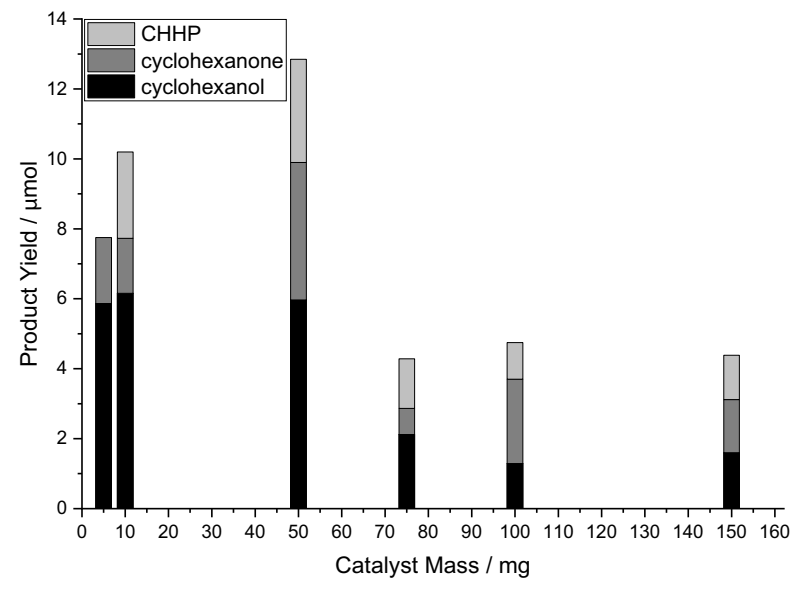

Fig. 4 The effect of catalyst mass on the oxidation of cyclohexane to KA oil. Reaction conditions Catalyst $(0.05 \mathrm{~g})$, cyclohexane $(2.13 \mathrm{~g}$, $25 \mathrm{mmol}$ ), t-butanol (6.37 g), $5 \% \mathrm{H}_{2} / \mathrm{N}_{2}$ (420 psi), $25 \% \mathrm{O}_{2} / \mathrm{N}_{2}(160$ psi), $17 \mathrm{~h}, 80^{\circ} \mathrm{C} 1200 \mathrm{rpm}$

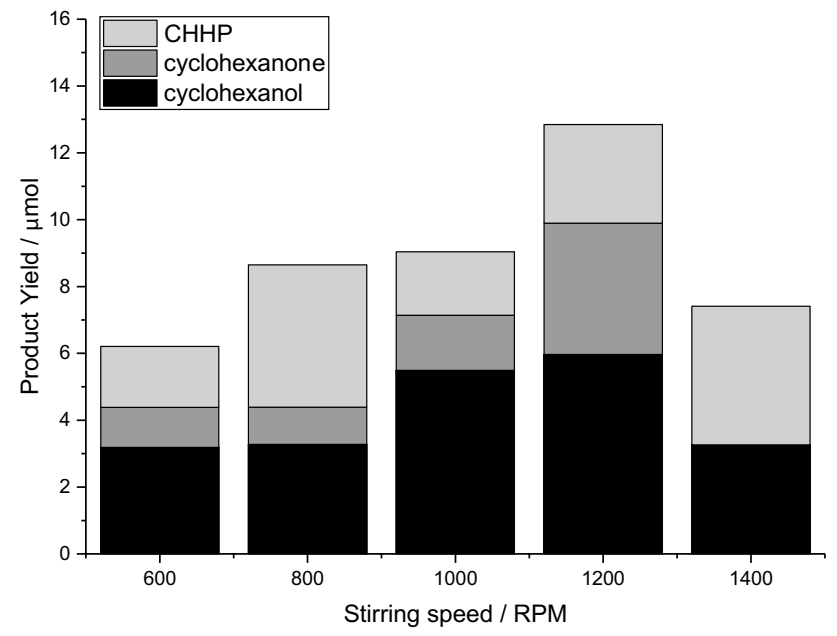

Fig. 5 Catalytic activity towards the selective oxidation of cyclohexane, via $\mathrm{H}_{2} \mathrm{O}_{2}$ synthesis as a function of stirring speed over a $0.5 \%$ $\mathrm{Au}-0.5 \% \mathrm{Pd} / \mathrm{TiO}_{2}$ catalyst. Reaction conditions Catalyst $(0.05 \mathrm{~g})$, cyclohexane (2.13 g, $25 \mathrm{mmol})$, t-butanol (6.37 g), $5 \% \mathrm{H}_{2} / \mathrm{N}_{2}(420$ psi), $25 \% \mathrm{O}_{2} / \mathrm{N}_{2}$ (160 psi), $17 \mathrm{~h}, 80{ }^{\circ} \mathrm{C} 1200 \mathrm{rpm}$

The effect of $\mathrm{H}_{2}: \mathrm{O}_{2}$ ratio was next investigated, while maintaining total reaction pressure at 580 psi (Fig. 6). A clear enhancement in KA oil yield is observed, with this metric increasing to a value of $47.6 \mu \mathrm{mol}$ under $\mathrm{H}_{2}$-rich conditions $\left(\mathrm{H}_{2}: \mathrm{O}_{2}=3.8\right)$. This is perhaps unsurprising given the first order dependence of $\mathrm{H}_{2} \mathrm{O}_{2}$ synthesis with respect to $\mathrm{H}_{2}$, while there is a zero order dependence with respect to $\mathrm{O}_{2}$ [33]. As such, at low $\mathrm{H}_{2}: \mathrm{O}_{2}$ ratios, where the reaction is limited by $\mathrm{H}_{2}$ availability, $\mathrm{H}_{2} \mathrm{O}_{2}$ production and in turn cyclohexane oxidation is limited.

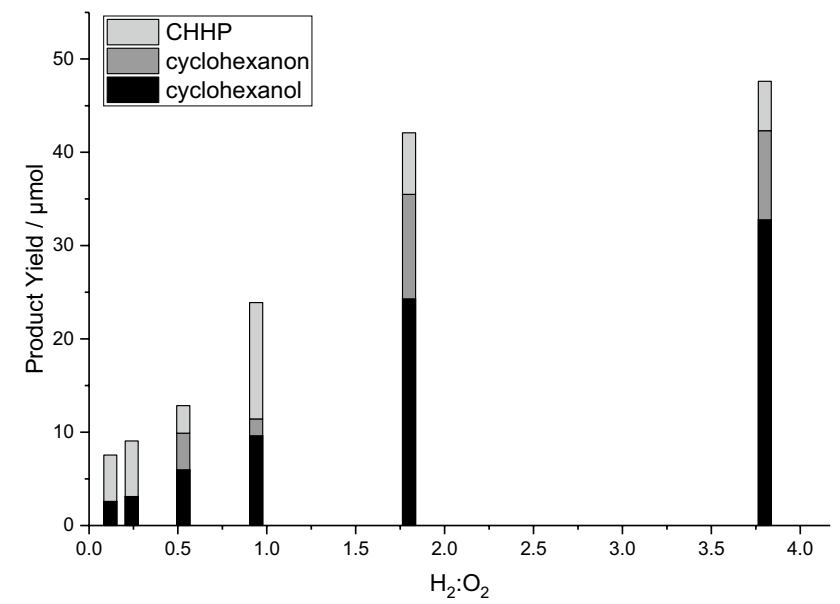

Fig. 6 Catalytic activity towards the selective oxidation of cyclohexane, via $\mathrm{H}_{2} \mathrm{O}_{2}$ synthesis as a function of $\mathrm{H}_{2}: \mathrm{O}_{2}$ over $0.5 \% \mathrm{Au}-0.5 \%$ $\mathrm{Pd} / \mathrm{TiO}_{2}$ catalyst. Reaction conditions Catalyst (0.05 g), cyclohexane (2.13 g, $25 \mathrm{mmol}$ ), t-butanol (6.37 g), 5\% $\mathrm{H}_{2} / \mathrm{N}_{2}$ (420 psi), 25\% $\mathrm{O}_{2} / \mathrm{N}_{2}$ (160 psi), $17 \mathrm{~h}, 80{ }^{\circ} \mathrm{C} 1200 \mathrm{rpm}$

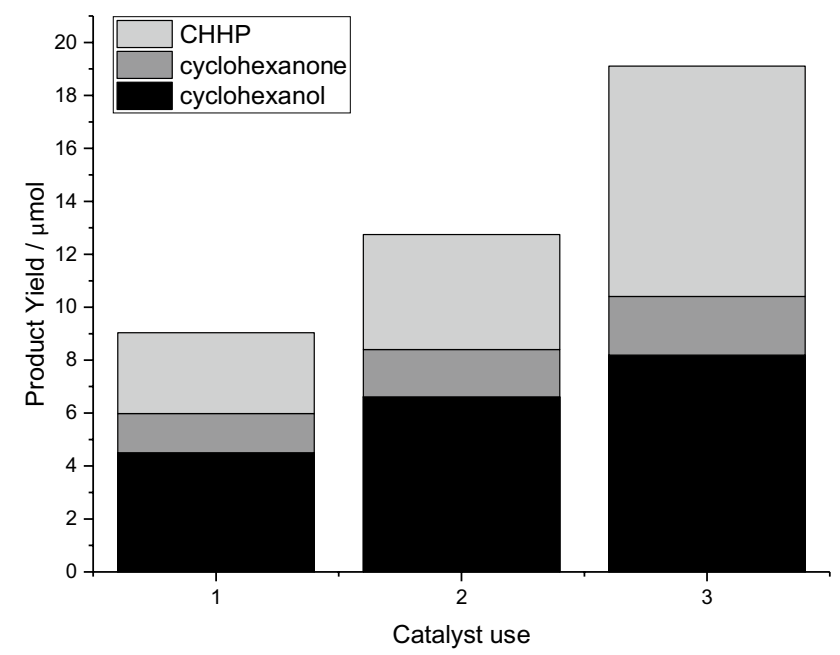

Fig. 7 Catalytic activity of $1 \% \mathrm{AuPd} / \mathrm{TiO}_{2}$ catalyst towards the oxidation of cyclohexane to KA oil with re-use. Reaction conditions Catalyst $(0.05 \mathrm{~g})$, cyclohexane $(2.13 \mathrm{~g}, 25 \mathrm{mmol})$, t-butanol $(6.37 \mathrm{~g}), 5 \%$ $\mathrm{H}_{2} / \mathrm{N}_{2}(420 \mathrm{psi}), 25 \% \mathrm{O}_{2} / \mathrm{N}_{2}(160 \mathrm{psi}), 17 \mathrm{~h}, 80^{\circ} \mathrm{C} 1200 \mathrm{rpm}$

Finally, with the requirement to re-use a catalyst successfully at the heart of green chemistry we next investigated catalytic activity of the $0.5 \% \mathrm{Au}-0.5 \% \mathrm{Pd} / \mathrm{TiO}_{2}$ catalyst towards cyclohexane oxidation upon re-use (Fig. 7), with previous studies reporting the high stability of supported AuPd nanoparticles for the oxidation of cyclohexane using molecular $\mathrm{O}_{2}$ [24].

Interestingly, it is possible to observe that catalytic activity increases substantially with re-use of the catalyst, with total product yield increasing from $9.0 \mu \mathrm{mol}$ for the fresh catalyst to $19.1 \mu \mathrm{mol}$ upon the third use. X-ray photoelectron spectroscopic 
Table 2 Summary of XPS derived surface atomic concentrations of $\mathrm{Au}$ and $\mathrm{Pd}$ present in $0.5 \% \mathrm{Au}-0.5 \% \mathrm{Pd} / \mathrm{TiO}_{2}$ catalyst over sequential cyclohexane oxidation reactions

\begin{tabular}{lll}
\hline Catalyst treatment & $\mathrm{Pd}: \mathrm{Au}$ & $\mathrm{Pd}^{0}: \mathrm{Pd}^{2+}$ \\
\hline $\begin{array}{l}\text { As prepared (calcined, } 3 \mathrm{~h} 400{ }^{\circ} \mathrm{C}, \\
\text { static air) }\end{array}$ & 18.5 & 1.3 \\
Use 1 & All Pd & 5.9 \\
Use 2 & All Pd & All $\mathrm{Pd}^{0}$ \\
Use 3 & All Pd & $\mathrm{All} \mathrm{Pd}^{0}$ \\
\hline
\end{tabular}

analysis of the fresh and used catalysts (Table 2) reveals a significant shift in Pd oxidation state with use. As expected, given the exposure to an oxidative heat treatment $\left(3 \mathrm{~h}, 400{ }^{\circ} \mathrm{C}\right.$, static air) the fresh $0.5 \% \mathrm{Au}-0.5 \% \mathrm{Pd} / \mathrm{TiO}_{2}$ catalyst is observed to predominantly consist of $\mathrm{Pd}^{2+}$. Indeed, we have previously demonstrated that upon calcination a Au-core Pd-shell nanoparticle morphology is typically adopted for AuPd catalysts supported on $\mathrm{TiO}_{2}$, with the adoption of this morphology often related to enhanced catalytic performance [20].

Upon sequential re-use in the cyclohexane oxidation reaction the Pd oxidation state is seen to shift, to consist entirely of $\mathrm{Pd}^{0}$, likely as a result of in-situ reduction of $\mathrm{Pd}^{2+}$ species. The enhanced activity of reduced Pd-species towards the direct synthesis of $\mathrm{H}_{2} \mathrm{O}_{2}$ is well known, with Burch and Ellis [34] and Liu et al. [35] reporting higher $\mathrm{H}_{2} \mathrm{O}_{2}$ production rates over supported $\mathrm{Pd}^{0}$ catalysts compared to $\mathrm{Pd}^{2+}$ analogues. As such it is possible to correlate the increase in KA oil production to an enhancement in $\mathrm{Pd}^{0}$ content.

Interestingly a stark shift in $\mathrm{Pd}$ : Au ratio is also observed with no Au signal detected after the catalyst is used in the cyclohexane oxidation reaction. With MP-AES analysis of the digested fresh and used $0.5 \% \mathrm{Au}-0.5 \% \mathrm{Pd} / \mathrm{TiO}_{2}$ catalysts revealing the high stability of the catalyst (Table S4) it is possible to rule out Au leaching as the factor responsible for the loss of observable Au in our XPS analysis.

Further study of the fresh and used catalysts via TEM (representative micrographs seen in Fig. S3) reveals that a bimodal distribution of nanoparticle size exists in the fresh catalyst, with similar findings by Herzing et al. [36] and Edwards et al. [37] previously reported for supported AuPd catalysts prepared by an analogous wet impregnation methodology. Indeed, detailed STEM-XEDS analysis has previously revealed a distinct relationship between particle size and elemental composition, with larger nanoparticles found to be Au-rich, while smaller nanoparticles are Pdrich [37]. Upon use in the cyclohexane oxidation reaction a substantial loss of the small, presumably Pd-rich nanoparticles is observed, with the resulting formation of larger AuPd agglomerates, presumably the likely cause for the loss of Au signal in our analysis by XPS. Previous studies by Williams et al. have highlighted the enhanced catalytic performance of larger AuPd nanoparticles for the selective oxidation of methane, using preformed $\mathrm{H}_{2} \mathrm{O}_{2}$ [38]. With this previous study in mind it is therefore possible to conclude that a combination of increased particle size and the formation of reduced Pd species are responsible for the enhanced activity observed upon re-use.

\section{Conclusion}

We have demonstrated that it is possible to achieve significant rates of cyclohexane oxidation to KA oil using $\mathrm{H}_{2} \mathrm{O}_{2}$ generated in-situ using a $1 \% \mathrm{AuPd} / \mathrm{TiO}_{2}$ catalyst, prepared by a readily scalable wet-impregnation procedure. This is observed using conditions where activity is limited when using molecular $\mathrm{O}_{2}$, with no loss in catalytic activity observed with re-use. We consider that these catalysts represent a promising basis for further exploration for the selective oxidation of a range of feed stocks.

Acknowledgements The authors with to acknowledge the financial support of and research discussion with Haldor Topsøe and the Cardiff University electron microscope facility for the transmission electron microscopy.

Data Availability The datasets generated during and/or analysed during the current study are available from the corresponding author on reasonable request.

\section{Compliance with Ethical Standards}

Conflict of interest The authors declare that they have no conflict of interest.

Open Access This article is licensed under a Creative Commons Attribution 4.0 International License, which permits use, sharing, adaptation, distribution and reproduction in any medium or format, as long as you give appropriate credit to the original author(s) and the source, provide a link to the Creative Commons licence, and indicate if changes were made. The images or other third party material in this article are included in the article's Creative Commons licence, unless indicated otherwise in a credit line to the material. If material is not included in the article's Creative Commons licence and your intended use is not permitted by statutory regulation or exceeds the permitted use, you will need to obtain permission directly from the copyright holder. To view a copy of this licence, visit http://creativecommons.org/licenses/by/4.0/.

\section{References}

1. Hamann JS, Hermsen M, Schmidt A-C, Kreig S, Schieß1 J, Riedel D, Teles JH, Schäfer A, Comba P, Hashmi ASK, Schaub T (2018) Selective Decomposition of cyclohexyl hydroperoxide using homogeneous and heterogeneous $\mathrm{Cr}^{\mathrm{VI}}$ catalysts: optimizing the reaction by evaluating the reaction mechanism. ChemCatChem 10:2755-2767

2. Peixoto de Almeida M, Martins LMDRS, Carabineiro SAC, Lauterbach T, Rominger F, Hashmi ASK, Pombeiro AJL, Figueiredo JL (2013) Homogeneous and heterogenised new gold 
C-scorpionate complexes as catalysts for cyclohexane oxidation. Catal Sci Technol 3:3056-3069

3. Hermans I, Jacobs PA, Peeters J (2006) To the core of autocatalysis in cyclohexane autoxidation. Chem Eur J 12:4229-4240

4. Xu Y-J, Landon P, Enache D, Carley AF, Roberts MW, Hutchings GJ (2005) Selective conversion of cyclohexane to cyclohexanol and cyclohexanone using a gold catalyst under mild conditions. Catal Lett 101:175-179

5. Carabineiro SAC, Martins LMDRS, Avalos-Borja M, Buijnsters JG, Pombeiro AJL, Figueiredo JL (2013) Gold nanoparticles supported on carbon materials for cyclohexane oxidation with hydrogen peroxide. Appl Catal A 467:279-290

6. Xu L-X, He C-H, Zhu M-Q, Wu K-J, Lai Y-L (2008) Surface stabilization of gold by sol-gel post-modification of alumina support with silica for cyclohexane oxidation. Catal Commun 9:816-820

7. Khare S, Shrivastava P (2016) Solvent-free oxidation of cyclohexane over covalently anchored transition-metal salicylaldimine complexes to $\alpha$-zirconium phosphate using tert-butylhydroperoxide. J Mol Catal A: Chem 411:279-289

8. Pires EL, Magalhães JC, Schuchardt U (2000) Effects of oxidant and solvent on the liquid-phase cyclohexane oxidation catalyzed by Ce-exchanged zeolite Y. Appl Catal A 203:231-237

9. Denicourt-Nowicki A, Lebedeva A, Bellini C, Roucoux A (2016) Highly selective cycloalkane oxidation in water with ruthenium nanoparticles. ChemCatChem 8:357-362

10. Santra C, Shah S, Mondal A, Pandey JK, Panda AB, Maity S, Chowdhury B (2016) Synthesis, characterization of VPO catalyst dispersed on mesoporous silica surface and catalytic activity for cyclohexane oxidation reaction. Microporous Mesoporous Mater 223:121-128

11. Du Y, Xiong Y, Li J, Yang X (2009) Selective oxidation of cyclohexane with hydrogen peroxide in the presence of copper pyrophosphate. J Mol Catal A: Chem 298:12-16

12. Armengol E, Corma A, Fornés V, Garcia H, Primo J (1999) $\mathrm{Cu} 2+-$ phthalocyanine and $\mathrm{Co} 2+-$ perfluorophthalocyanine incorporated inside Y faujasite and mesoporous MCM-41 as heterogeneous catalysts for the oxidation of cyclohexane. Appl Catal A 181:305-312

13. Carvalho WA, Wallau M, Schuchardt U (1999) Iron and copper immobilised on mesoporous MCM-41 molecular sieves as catalysts for the oxidation of cyclohexane. J Mol Catal A: Chem 144:91-99

14. Spinace EV, Pastore HO, Schuchardt U (1995) Cyclohexane Oxidation catalyzed by titanium silicalite (TS-1): overoxidation and comparison with other oxidation systems. J Catal 157:631-635

15. Crole DA, Freakley SJ, Edwards JK, Hutchings GJ (2016) Direct synthesis of hydrogen peroxide in water at ambient temperature. Proc R Soc A 472:20160156

16. Scoville JR, Novicova IA (1996) Hydrogen peroxide disinfecting and sterilizing compositions. US5900256

17. Wegner $P$ (2003) Hydrogen peroxide stabilizer and resulting product and applications. US20050065052A1

18. Lewis RJ, Ueura K, Fukuta Y, Freakley SJ, Kang L, Wang R, He Q, Edwards JK, Yamamoto MDJ, Hutchings GJ (2019) The direct synthesis of $\mathrm{H}_{2} \mathrm{O}_{2}$ using TS-1 supported catalysts. ChemCatChem 11:1673-1680

19. Scofield JH (1976) Hartree-Slater subshell photoionization crosssections at 1254 and $1487 \mathrm{eV}$. J Electron Spectrosc Relat Phenom $8: 129-137$

20. Edwards JK, Solsona BE, Landon P, Carley AF, Herzing A, Kiely CJ, Hutchings GJ (2005) Direct synthesis of hydrogen peroxide from $\mathrm{H}_{2}$ and $\mathrm{O}_{2}$ using $\mathrm{TiO}_{2}$-supported $\mathrm{Au}-\mathrm{Pd}$ catalysts. J Catal 236:69-79

21. Wu P, Cao Y, Zhao L, Wang Y, He Z, Xing W, Bai P, Mintova S, Yan Z (2019) Formation of PdO on Au-Pd bimetallic catalysts and the effect on benzyl alcohol oxidation. J Catal 375:32-43
22. Agarwal N, Freakley SJ, McVicker RU, Althaban SM, Dimitratos N, He Q, Morgan DJ, Jenkins RL, Willock DJ, Taylor SH, Kiely CJ, Hutchings GJ (2017) Aqueous Au-Pd colloids catalyze selective $\mathrm{CH}_{4}$ oxidation to $\mathrm{CH}_{3} \mathrm{OH}$ with $\mathrm{O}_{2}$ under mild conditions. Science 358:223-227

23. Bianchi CL, Canton P, Dimitratos N, Porta F, Prati L (2005) Selective oxidation of glycerol with oxygen using mono and bimetallic catalysts based on Au. Pd and Pt metals Catal Today 102-103:203-212

24. Liu X, Conte M, Sankar M, He Q, Murphy DM, Morhan DJ, Jenkins RL, Knight D, Whiston K, Kiely CJ, Hutchings GJ (2015) Liquid phase oxidation of cyclohexane using bimetallic $\mathrm{Au}-\mathrm{Pd} /$ $\mathrm{MgO}$ catalysts. Appl Catal A 504:373-380

25. Li G, Edwards J, Carley AF, Hutchings GJ (2007) Direct synthesis of hydrogen peroxide from $\mathrm{H}_{2}$ and $\mathrm{O}_{2}$ and in situ oxidation using zeolite-supported catalysts. Catal Commun 8:247-250

26. Zhao R, Ji D, Gaomeng L, Yan L, Wang X, Suo J (2004) A highly efficient oxidation of cyclohexane over Au/ZSM-5 molecular sieve catalyst with oxygen as oxidant. Chem Commun 2:904-905

27. Lü G, Zhao R, Qian G, Oi Y, Wang X, Suo J (2004) A highly efficient catalyst $\mathrm{Au} / \mathrm{MCM}-41$ for selective oxidation cyclohexane using oxygen. Catal Lett 97:115-118

28. Alfayate A, Márquez-Álvarez C, Grande-Casas M, BernardoMaestro S-S, Perez-Pariente J (2013) Enhanced catalytic activity of TAPO-5 in the oxidation of cyclohexene with hydrogen peroxide under anhydrous conditions. Catal Today 213:211-218

29. Santos A, Lewis RJ, Malta G, Howe AGR, Morgan DJ, Mapton E, Gaskin P, Hutchings GJ (2019) Direct synthesis of hydrogen peroxide over $\mathrm{Au}-\mathrm{Pd}$ supported nanoparticles under ambient conditions. Ind Eng Chem Res 58:12623-12631

30. Huang G, Guo C-C, Tang S-S (2007) Catalysis of cyclohexane oxidation with air using various chitosan-supported metallotetraphenylporphyrin complexes. J Mol Catal A: Chem 261:125-130

31. Landon P, Collier PJ, Carley AF, Chadwick D, Papworth AJ, Burrows A, Kiely CJ, Hutchings GJ (2003) Direct synthesis of hydrogen peroxide from $\mathrm{H}_{2}$ and $\mathrm{O}_{2}$ using $\mathrm{Pd}$ and Au catalysts. Phys Chem Chem Phys 5:1917-1923

32. Piccinini M, Edwards JK, Moulijn JA, Hutchings GJ (2012) Influence of reaction conditions on the direct synthesis of hydrogen peroxide over AuPd/carbon catalysts. Catal Sci Technol 2:1908-1913

33. Liu Q, Bauer JC, Schaak RE, Lunsford JH (2008) Direct synthesis of $\mathrm{H}_{2} \mathrm{O}_{2}$ from $\mathrm{H}_{2}$ and $\mathrm{O}_{2}$ over $\mathrm{Pd}-\mathrm{Pt} / \mathrm{SiO}_{2}$ bimetallic catalysts in $\mathrm{a}_{2} \mathrm{SO}_{4}$ /ethanol system. Appl Catal A 339:130-136

34. Burch R, Ellis PR (2003) An investigation of alternative catalytic approaches for the direct synthesis of hydrogen peroxide from hydrogen and oxygen. Appl Catal B 42:203-211

35. Liu Q, Gath KK, Bauer JC, Schaak LJH (2009) The active phase in the direct synthesis of $\mathrm{H} 2 \mathrm{O} 2$ from $\mathrm{H}_{2}$ and $\mathrm{O}_{2}$ over $\mathrm{Pd} / \mathrm{SiO}_{2}$ catalyst in $\mathrm{a}_{2} \mathrm{SO}_{4}$ /ethanol system. Catal Lett 132:342

36. Herzing AA, Watanabe M, Edwards JK, Conte M, Tang Z-R, Hutchings GJ, Kiely CJ (2008) Energy dispersive X-ray spectroscopy of bimetallic nanoparticles in an aberration corrected scanning transmission electron microscope. Faraday Discuss 138:337-351

37. Edwards JK, Carley AF, Herzing AA, Kiely CJ, Hutchings GJ (2008) Direct synthesis of hydrogen peroxide from $\mathrm{H}_{2}$ and $\mathrm{O}_{2}$ using supported Au-Pd catalysts. Faraday Discuss 138:225-239

38. Williams C, Carter JH, Dummer NF, Chow YK, Morgan DJ, Yacob S, Serna P, Willock DJ, Meyer RJ, Taylor SH, Hutchings GJ (2018) Selective oxidation of methane to methanol using supported AuPd catalysts prepared by stabilizer-free sol-immobilization. ACS Catal 8:2567-2576

Publisher's Note Springer Nature remains neutral with regard to jurisdictional claims in published maps and institutional affiliations. 